\title{
PLANO DE MASSAS - UM INSTRUMENTO PARA O DESENHO DA PAISAGEM
}

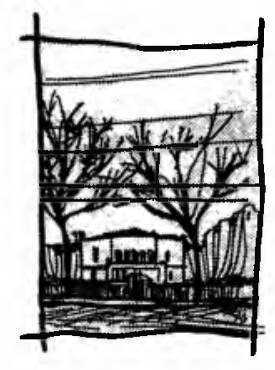

SILVIO SOARES MACEDO

Dentro do processo de "desenho" dos espaços livres várias são as etapas percorridas até se chegar na construção e uso da paisagem desejada. Após os primeiros estudos, definições e seleção da área de intervenção, da sua interpretação, análise e diagnóstico, obtém-se um plano geral da paisagem - expresso através de um zoneamento espacial e funcional da área em questão. O processo de projeto continua através de outras tantas etapas como o plano de massas, anteprojeto, projeto, obras no local, etc., até que o determinado espaço venha a ser utilizado pelo seu usuário.

Este textoé uma introdução sobre uma etapa do processo - o plano de massas - de modo a dar uma visão geral desta etapa e de suas implicações na paisagem em construção.

\section{SOBRE UM PLANO DE MASSA}

Oplano de massaé oestudo preliminar da paisagem,quando se define a estrutura básica dos espaços a serem produzidos, suas características de uso, forma, cor, textura, os caminhos, etc.

Nesta etapa do processo de projetar o espaço se configura pela primeira vez o "desenho" da paisagem desejada, em um tempo/espaço definidos, baseado nos estudos efetuados anteriormente sobre a área em questão e que resultaram em um plano geral - o zoneamento.

Um plano de massa serve de apoio para o projeto final, pois nele é estudada a configuração da futura paisagem a ser produzida. É uma etapa de questionamento do plano proposto através doestudo das possibilidades espaciais que este plano induz sobre um sítio determinado. Para cada item do plano, bem como para seu conjunto, são produzidas alternativas espaciais, que depois de analisadas e selecionadas levam a um "esboço" da paisagem final pretendida.

Este conjunto produzido, depois de questionado e avaliado pelos diversos setores interessados na produção da paisagem e modificado se necessário é transformado em um anteprojeto. 


\section{GRAU DE DEFINIÇÃO}

Nesta etapa do processo de projeto determinam-se todos os elementos formadores da paisagem de modo que cada espaço, cada pátio, clareira, caminho tem determinadas as suas formas e dimensões básicas, sendo caracterizados seus pisos, planos e volumes de vegetação, muros, esquemas e volumes edificados.

Considerando o projeto de um parque como exemplo, caracterizam-se os seguintes itens:

Configuração do Sítio - De acordo com o plano geral do parque são indicados os planos e níveis a serem produzidos destinados a acomodar os diversos espaços e atividades especificados. São apontados os principais movimentos de terra de modo a criar o suporte adequado à nova situação com uma drenagem correta, um assentamento e correção do solo de modo a receber edifícios, pisos e plantação.

Caminhos - Determinados de acordo com um esquema geral de circulação de pedestres e veículos. São dimensionadas e especificadas as características básicas de piso, se este é permeável ou impermeável e as obras necessárias de modo a conter o terreno, ultrapassar as águas, etc., tais como muros de arrimo, pontes e aterros. São ainda sugeridos critérios de iluminação e sinalização base, de modo a fornecer subsídios para uma futura especificação e são configurados os planos de vegetação vizinhos ao percurso.

A vegetação ao longo dos caminhos tem, no caso de um parque, um papel estruturador de planos horizontais e verticais, "paredes" pisos e coberturas, que tem então suas características básicas definidas, isto é, graus de fechamento, transparências, cores, texturas. Os aromas exalados pelas diversas espécies, o movimento das folhas e galhos ao vento contribuem para uma identificação dos espaços criados ao redor das trilhas, corredores, etc.

A cada um deles é atribuído um grau de importância de acordo com as necessidades de uso principais, secundárias, etc., correspondendo ainda a cada categoria de utilização, dimensões e tipos de piso diferentes.

Aos caminhos principais, aquele que percorrem a área inteira, que definem ou circundam setores principais correspondem aos de maior uso, diversificados e intenso, necessitando de pisos permeáveis e de fácil escoamento das águas, manutenção constante e de maior dimensão.

São aqueles que comportam atividades simultâneas como andar a pé, de bicicleta, pequenos veículos, etc., atividades estas setorizadas ou não, em pisos diferentes. 


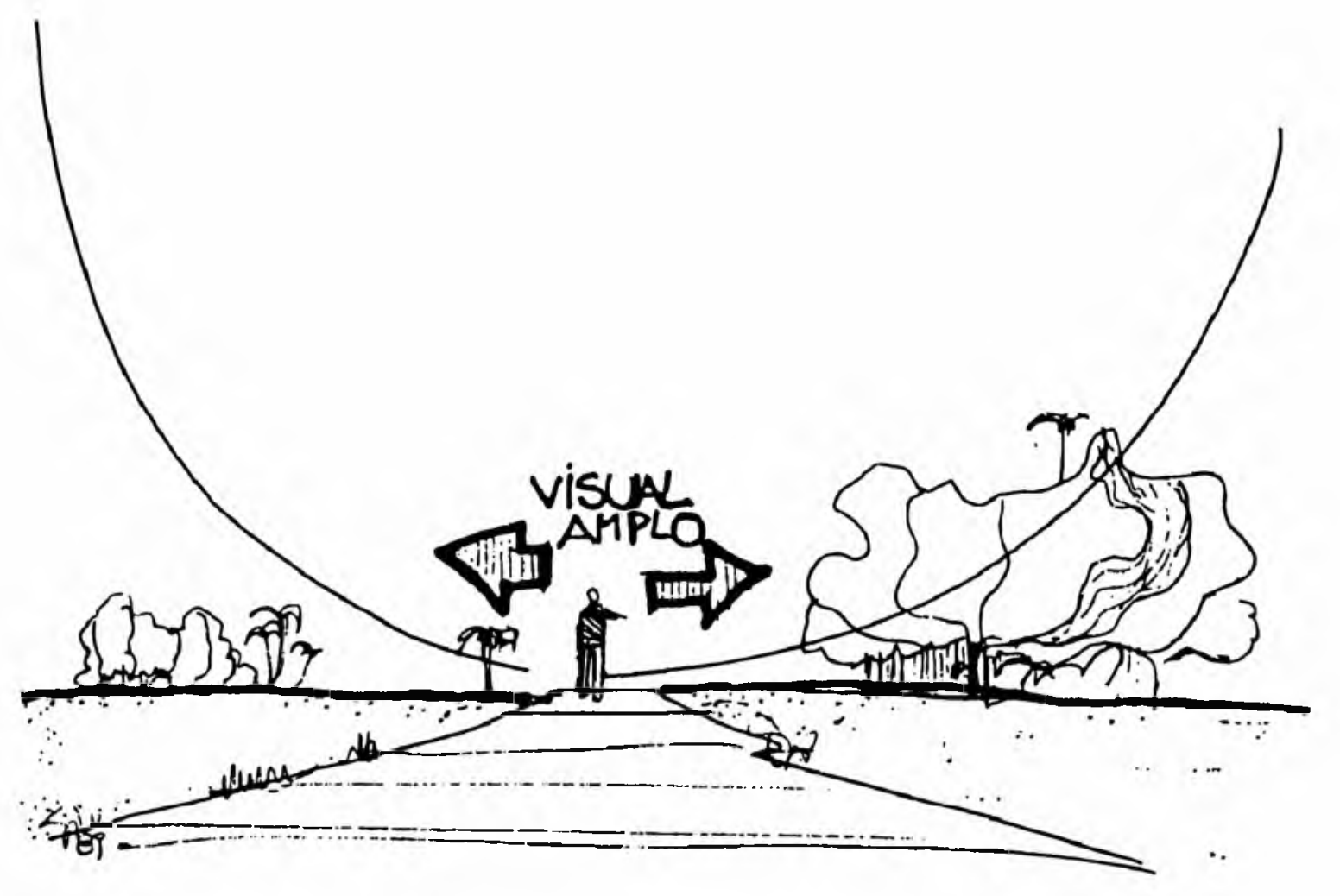

Os caminhos destinados predominantemente ao uso por pedestres comportam pisos variados e de baixa resistência à cargas.

A utilização por veículos pesados implica em uma escolha mais específica de materiais, mais resistentes a cargas pesadas.

Os caminhos secundários destinados a usos específicos, como pistas beira água, para a caminhada lenta, para a contemplação da paisagem, como trilhas em meio a bosques, etc.,podem tertratamentos de pisoe dimensõesmaismodestas devidoaoseu próprio usomais restrito, como serão mais longos do que o necessário a uma circulação rápida e imediata.

Qualquer tipo de caminho comporta durante seu percurso, intervenções, clareiras, pátios, mirantes, de modo a permitir ao usuário opções de parada para descanso, beber água, contemplação, etc. 


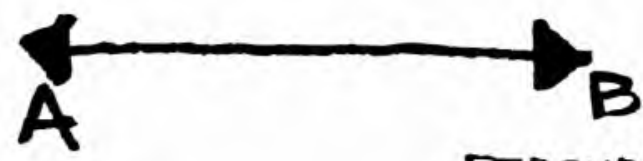

PERCURSO

DIRETO
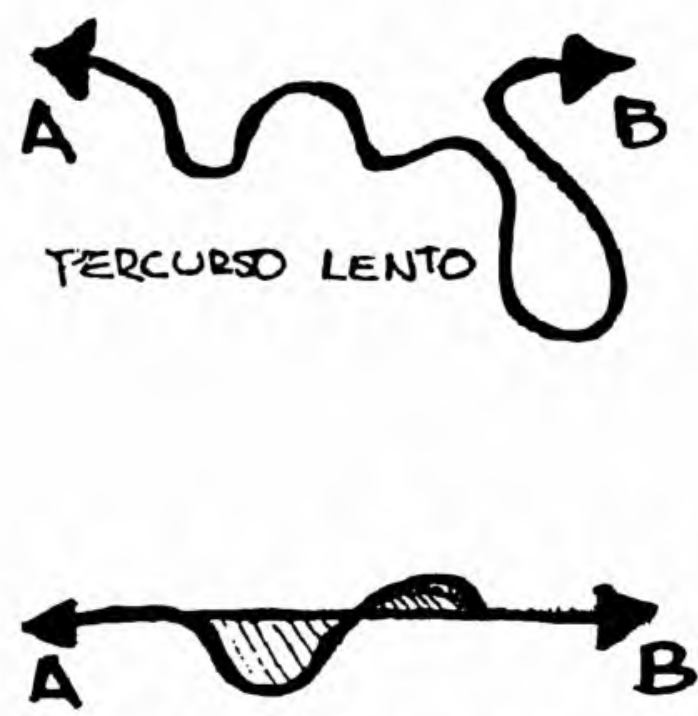

PERCURSO DIRETO COM A'REAS DE PARADAS

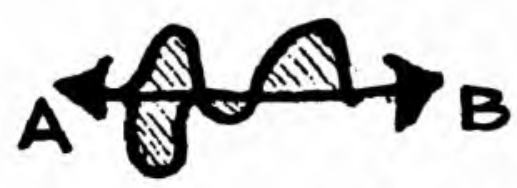

PERCURSO

DIDETO

COY ÁREA

PARA PARAMS

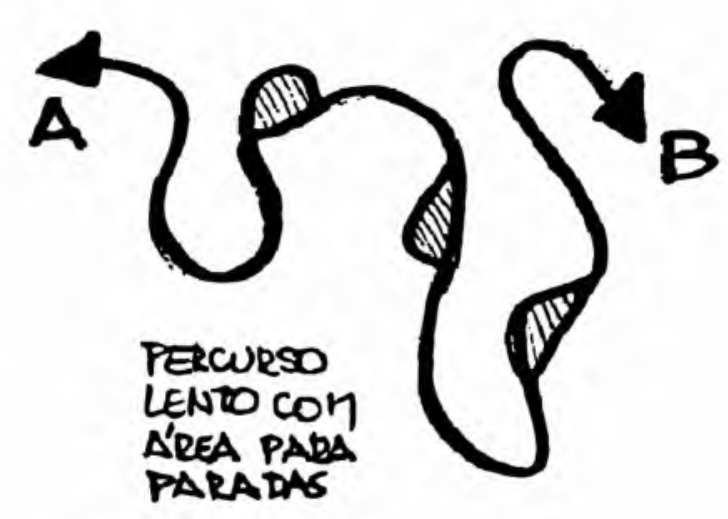

\section{ESPAÇOS DETERMINADOS EXCLUSIVAMENTE PELA VEGETAÇÃO}

São asclareiras, campos, bosques, gramados destinadosa viveiros, para reserva natural, santuários de animais e para o uso público, seja este simplesestar como passeios, sentar, dormir, comer um lanche... para jogos.

Cada um deles varia sua configuração de acordo com a estrutura do elemento vegetal utilizado, sua forma e quantidade, critérios de assentamento, predominância, altura, textura, cor e transparência. 

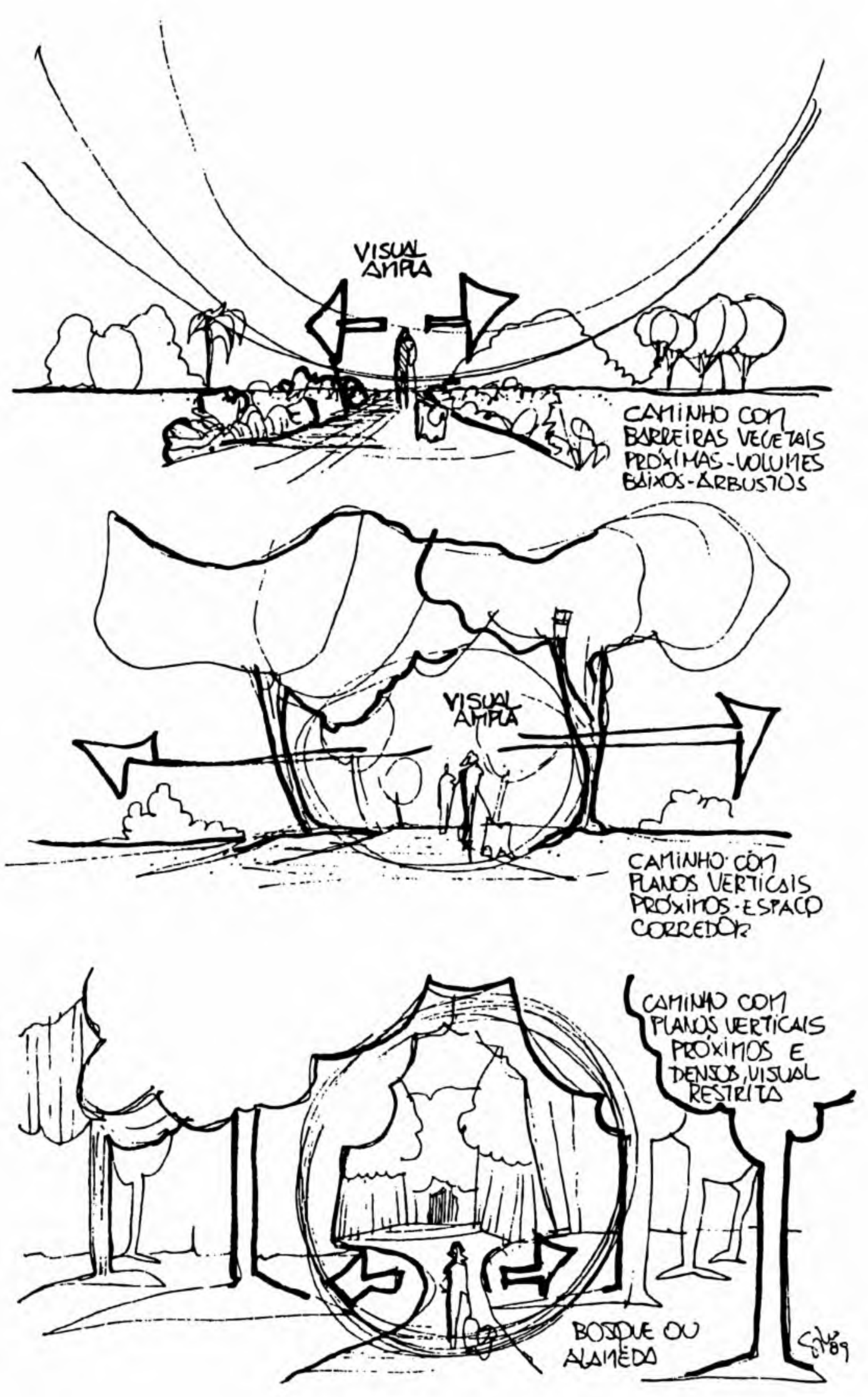

13 

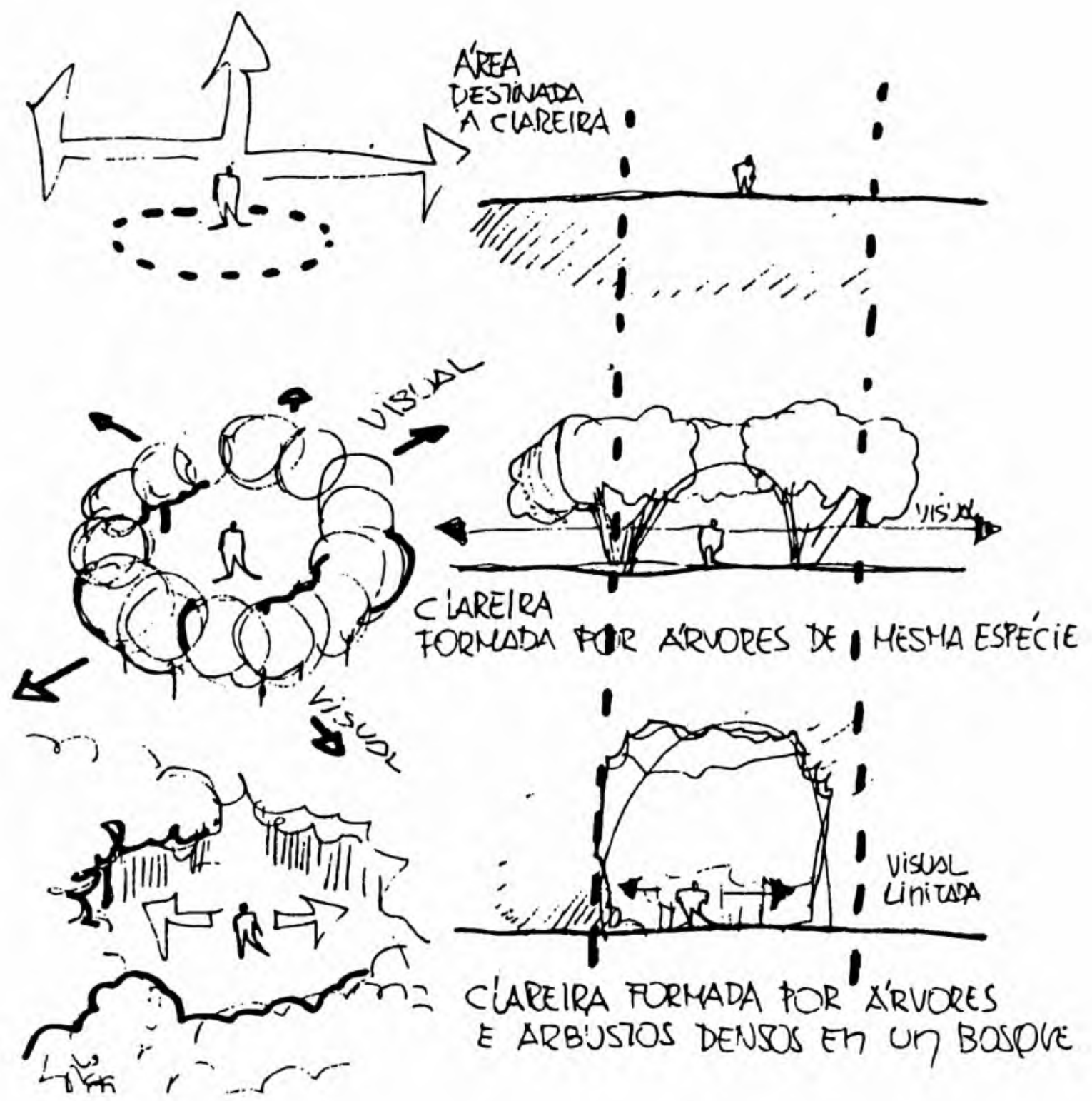

Volumes Vegetais Básicos - Tradicionalmente se identifica uma série de volumes que caracterizam as diversas formas de vegetação existente. Considerados isoladamente têm pouca importância na configuração geral de determinados espaços livres, principalmente nos espaços de grande e médio porte. No caso de um parque, uma grande praça, etc., os conjuntos formados pelos diferentes tipos de vegetação são fatores determinantes da organização e produção dos espaços e nunca um elemento isolado. No caso de um pequeno pátio, de uma pracinha um elemento único, uma árvore por exemplo, pode ser estrutural, quase sempre, entretanto, dependendo de conjuntos de outras espécies de porte menor, dos pisos e edifícios do entorno como elementos complementares. 


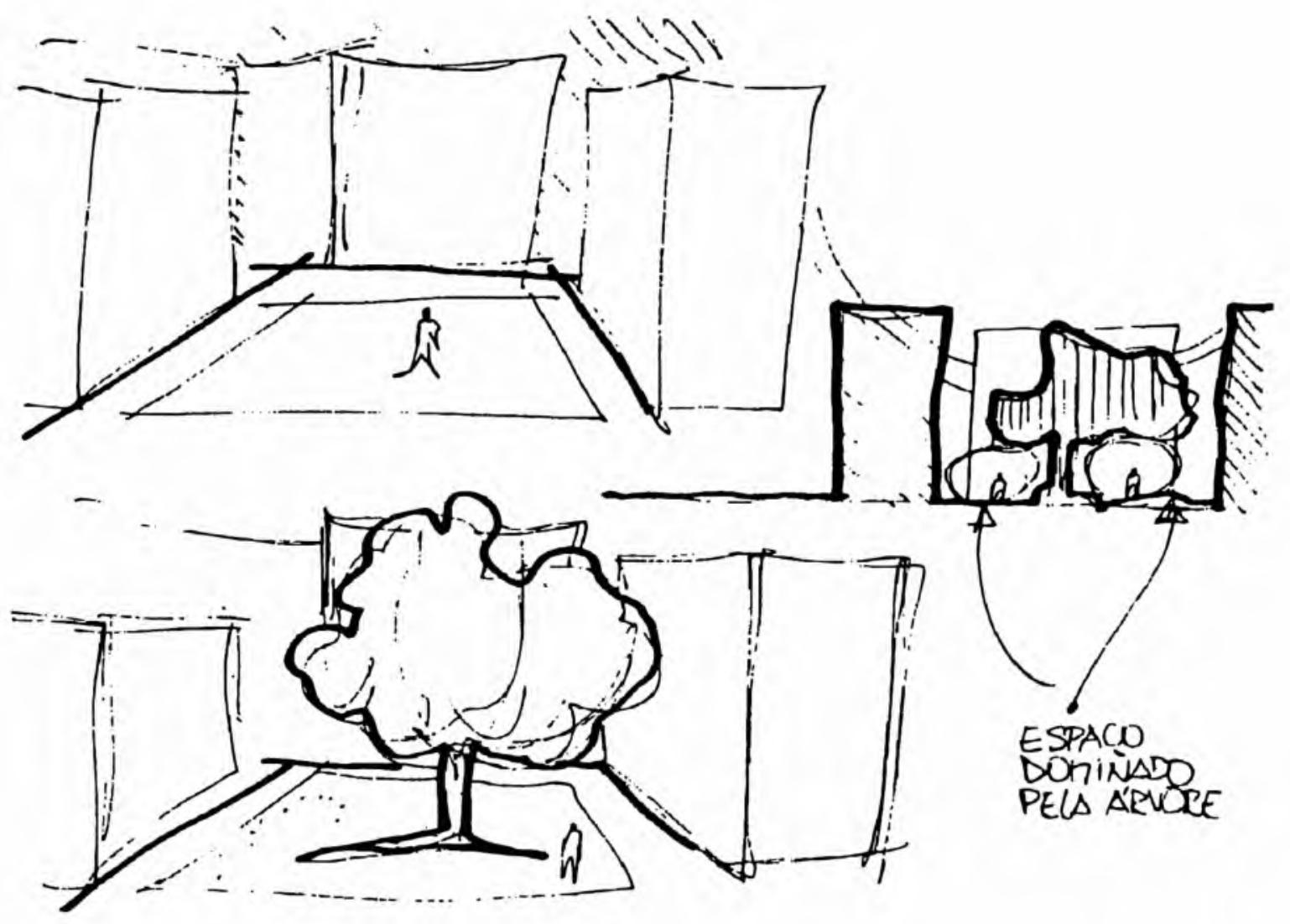

Os elementos vegetais isolados nos grandes espaços livres existem e devem ser considerados como componentes complementares de cada área, como um detalhe, um referencial, um marco, etc.

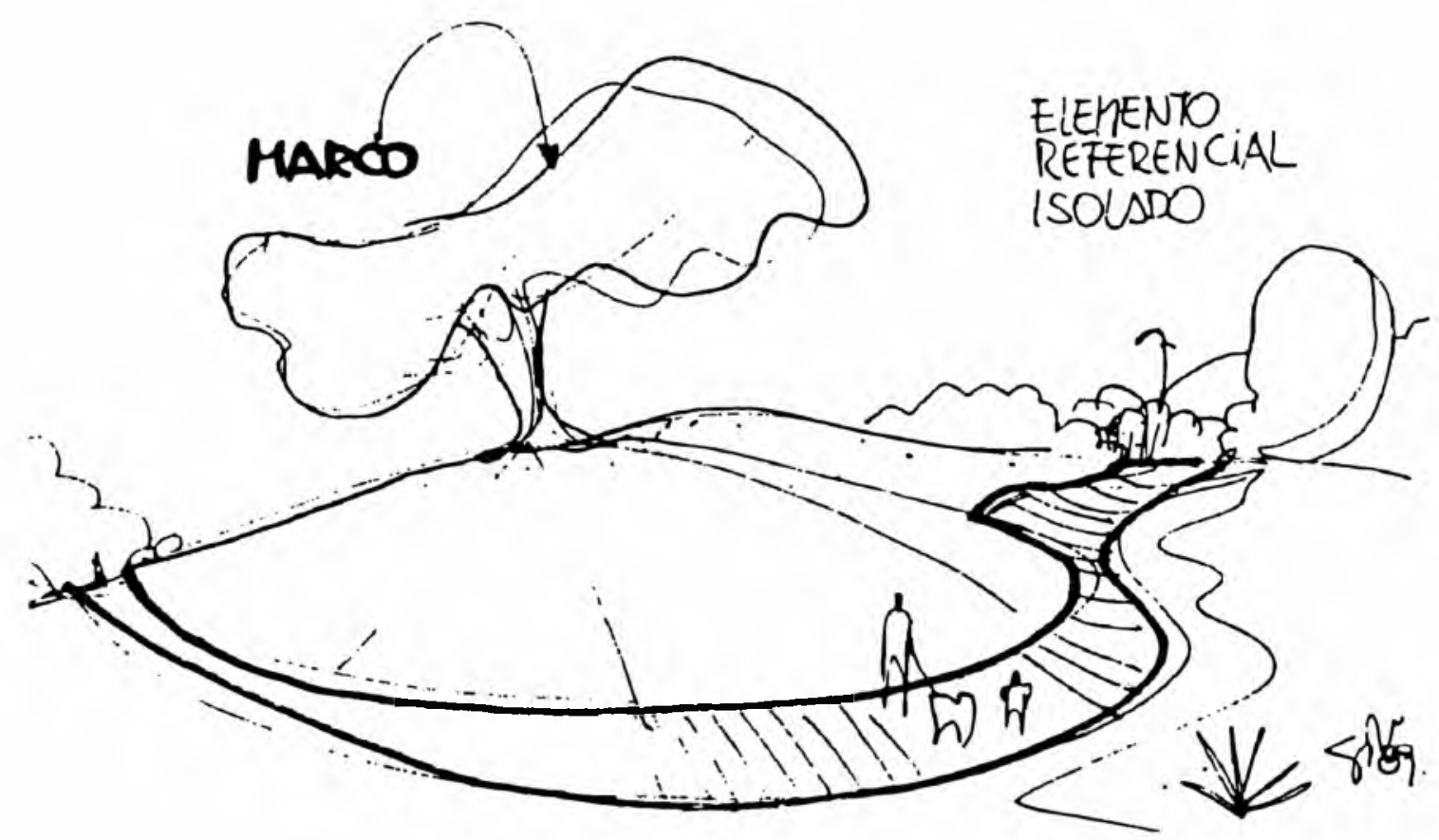

15 
Para efeito de estudo distinguem-se tradicionalmente uma série de categorias de volumes vegetais de acordo com a configuração de sua ramagem ou volume. Cada um deles utilizado isoladamente, misturados entre si ou agrupados possibilitam a criação de uma gama infinita de espaço. Tem-se a seguir exemplos de algumas das principais categorias encontradas.

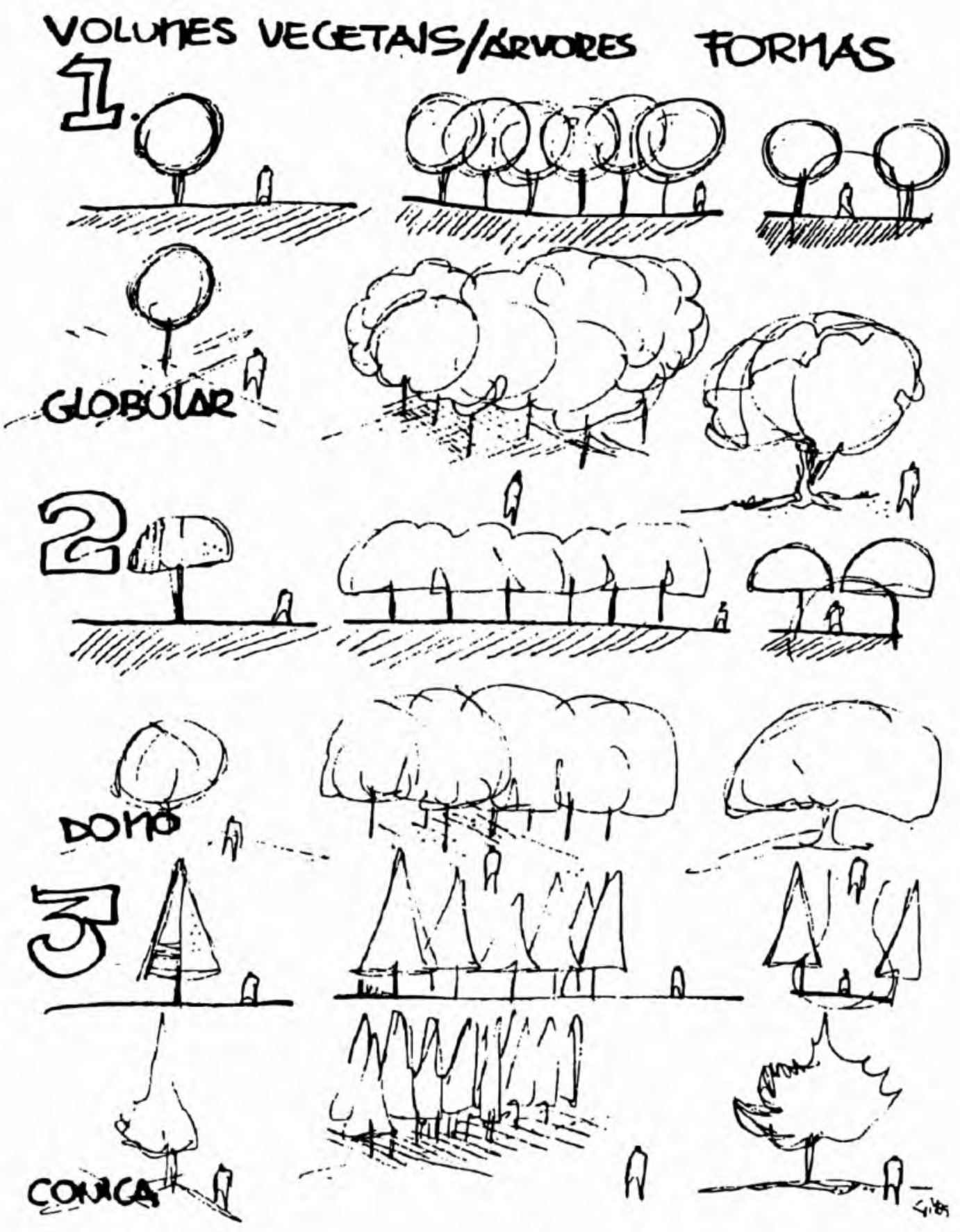


VOLUNES VEGETAS/ÁRVORES - FORHAS

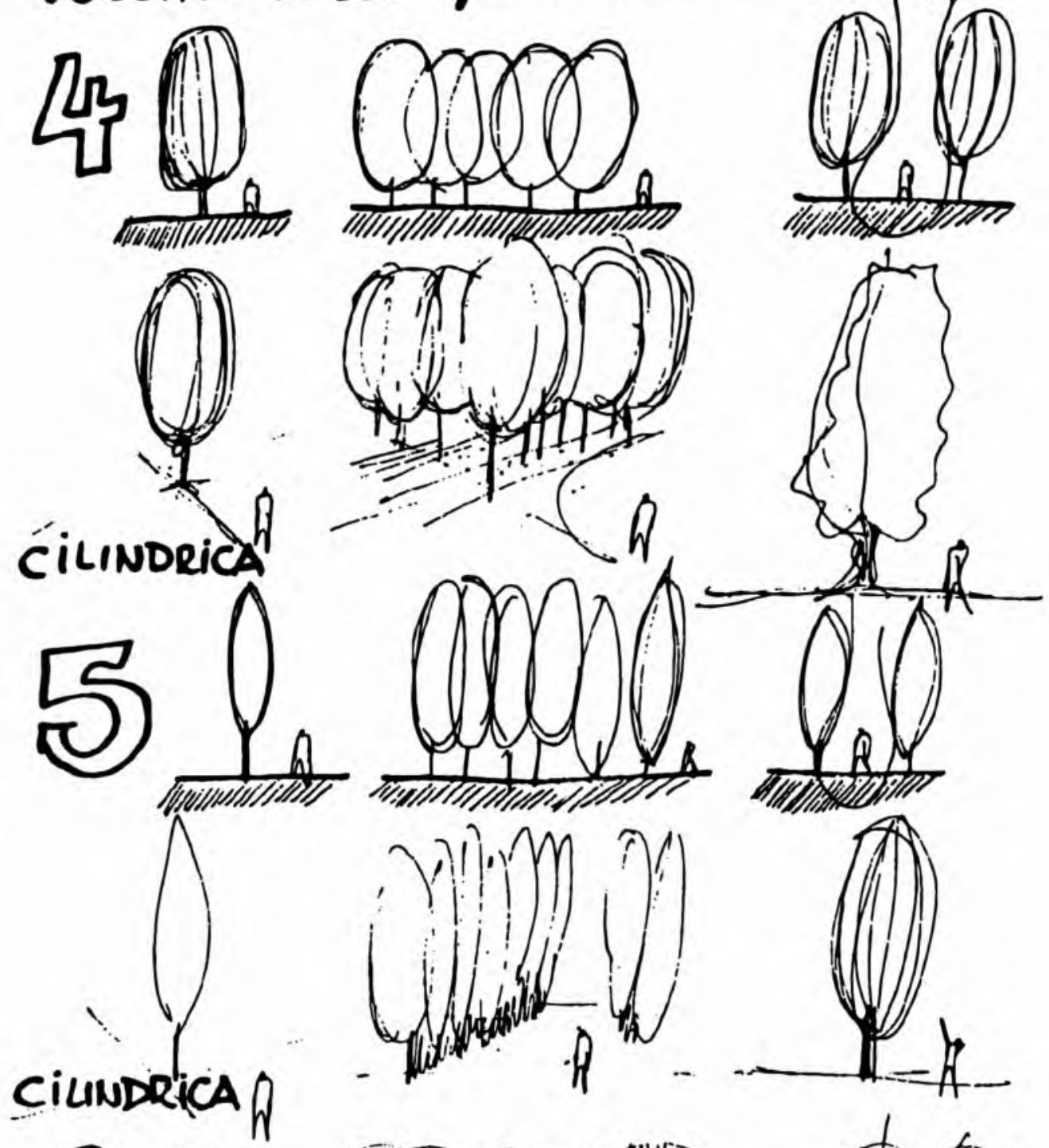

(6)
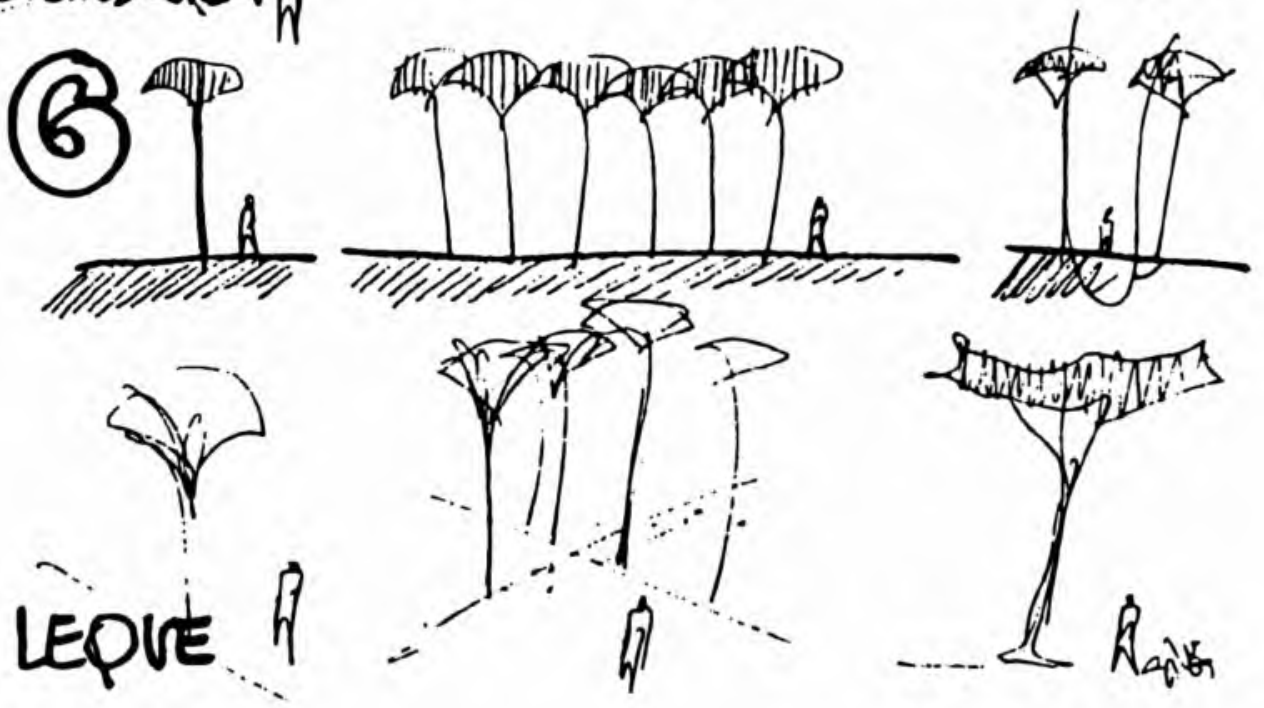

17 


\section{VOLUNES VEGETAIS/R'RVORES - FORMAS}
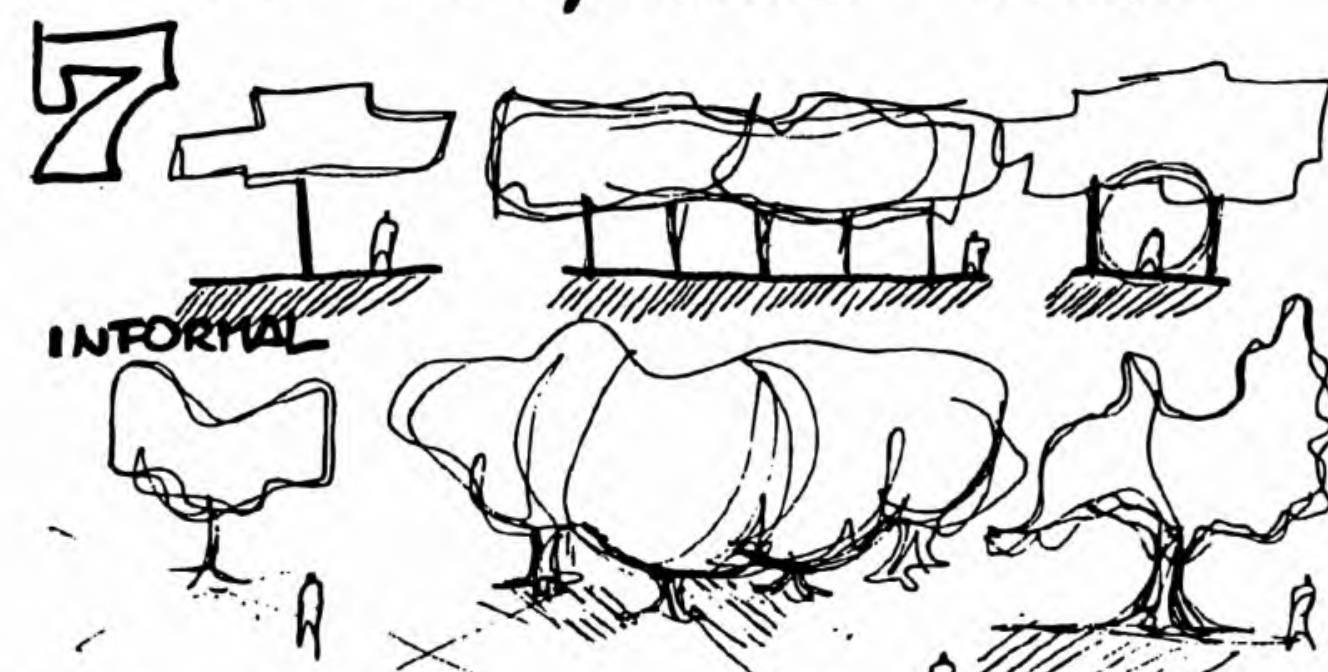


\section{$\triangle R B U S 70 S$.}
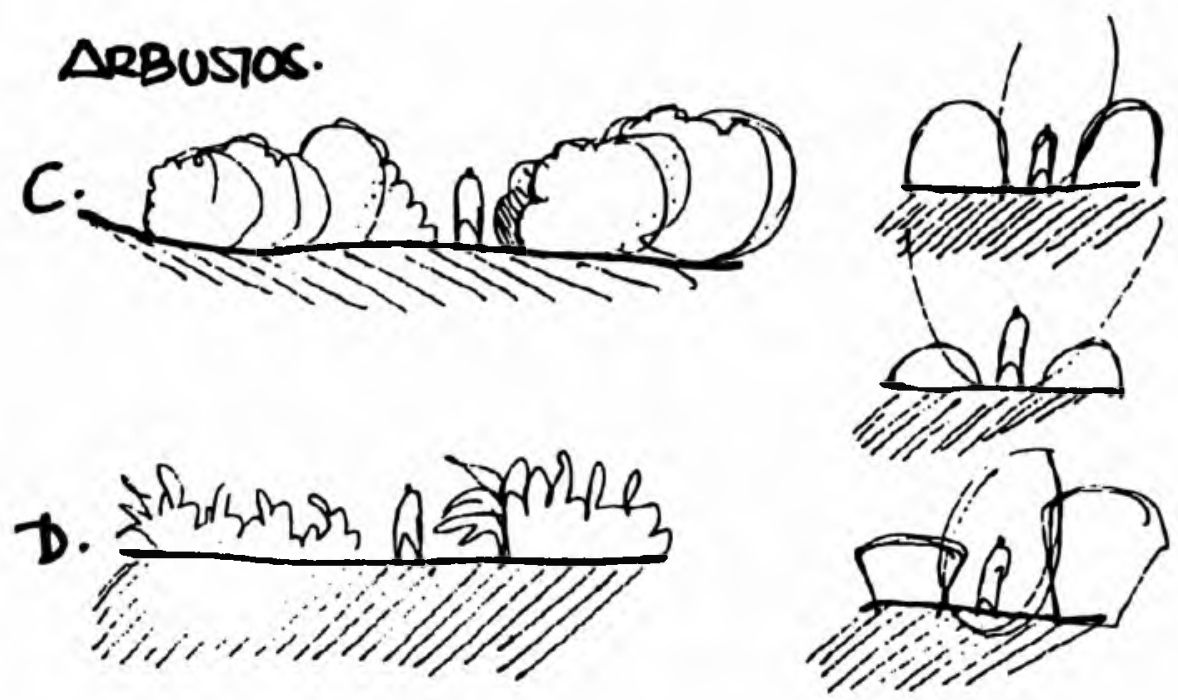

\section{VOUMES VEGETALS}

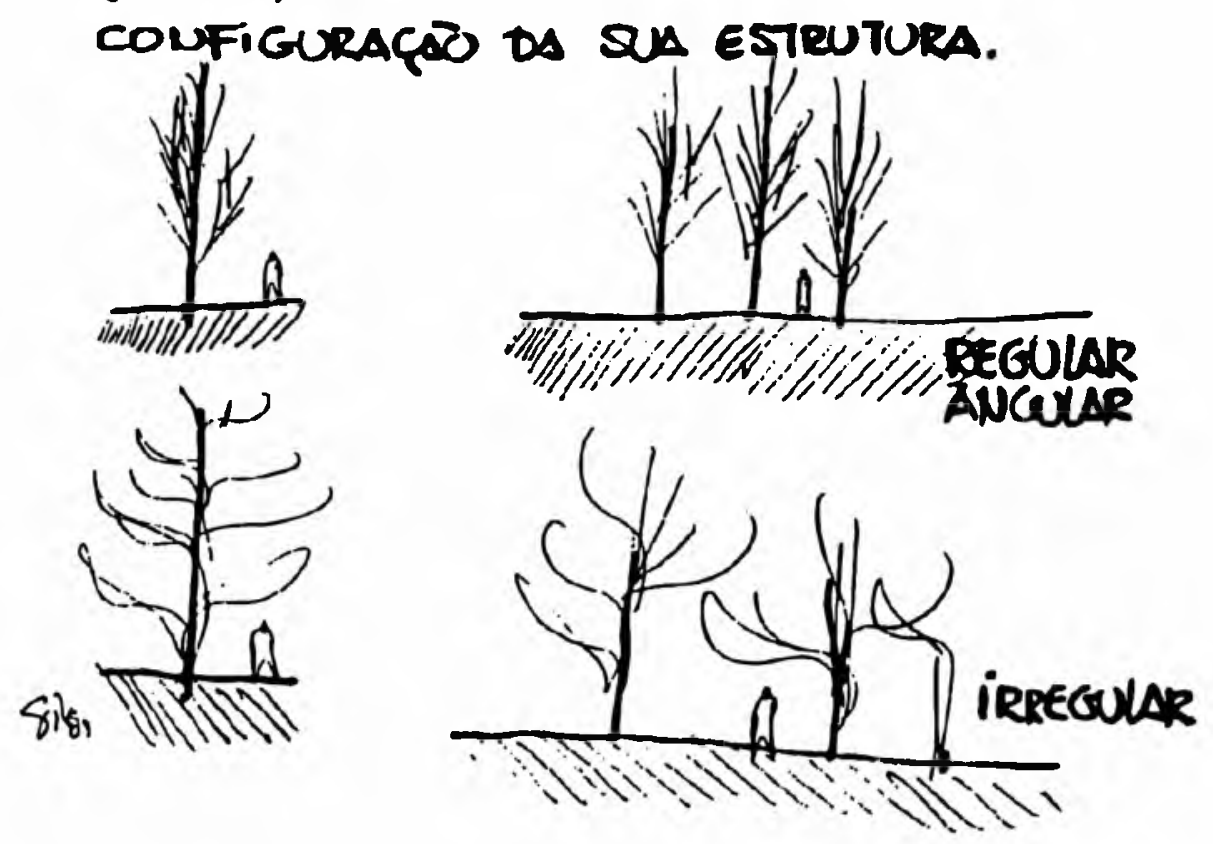

Um determinado espaço, conforme a estrutura vegetal dominante, tem uma característica especial. Considerando por exemplo uma clareira a ser formada se ela é aberta em meio a uma mata fechada ou em meio a um renque de árvores de copa vertical, possui uma expressão espacial diferente apesar de apresentar as mesmas dimensões horizontais. O mesmo se dará se os elementos dominantes são pinheiros (estruturas de forma colunar), coqueiros, etc. 
para MESTPS ESPACQS EN PISO conficurapós dFERENTES
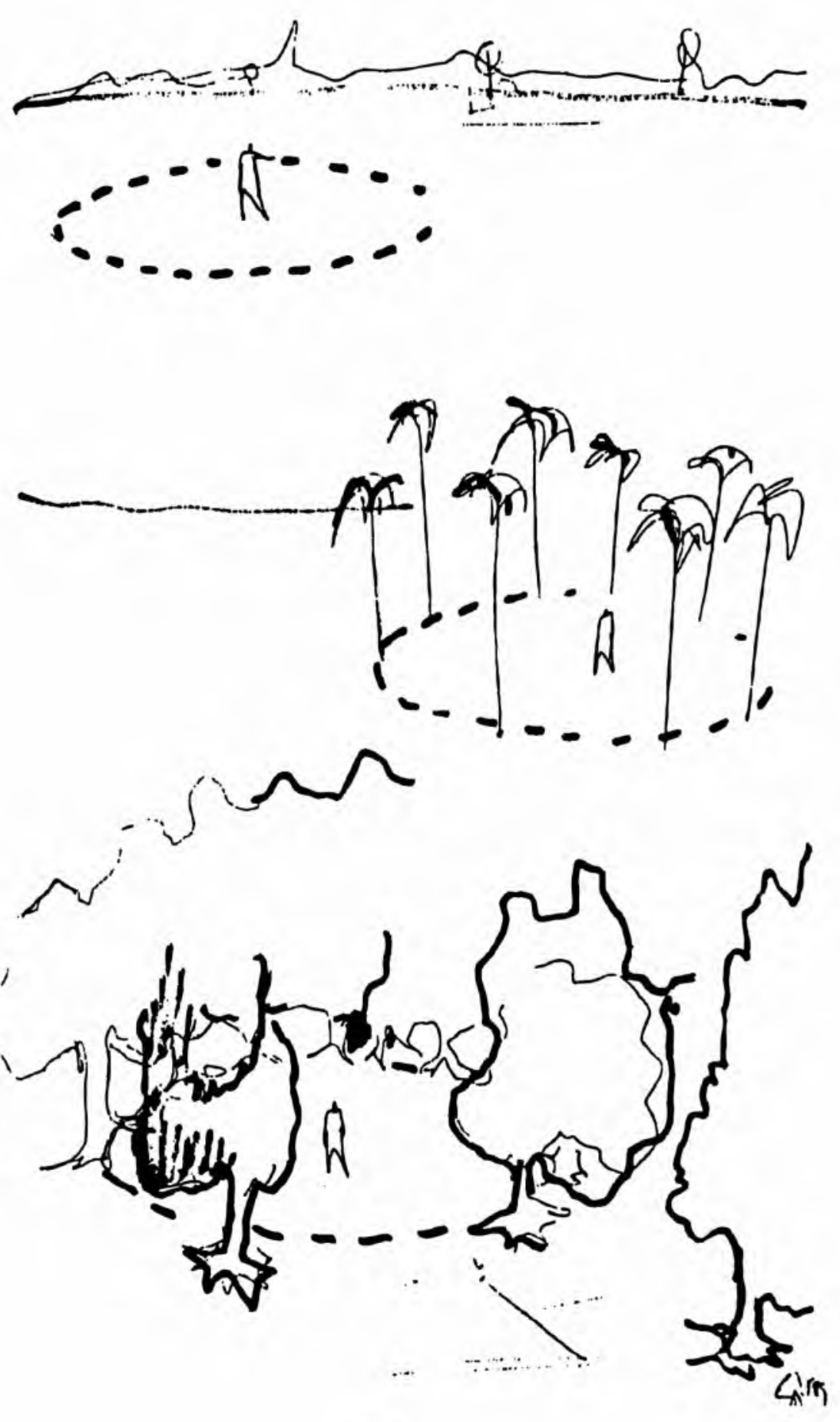

20 

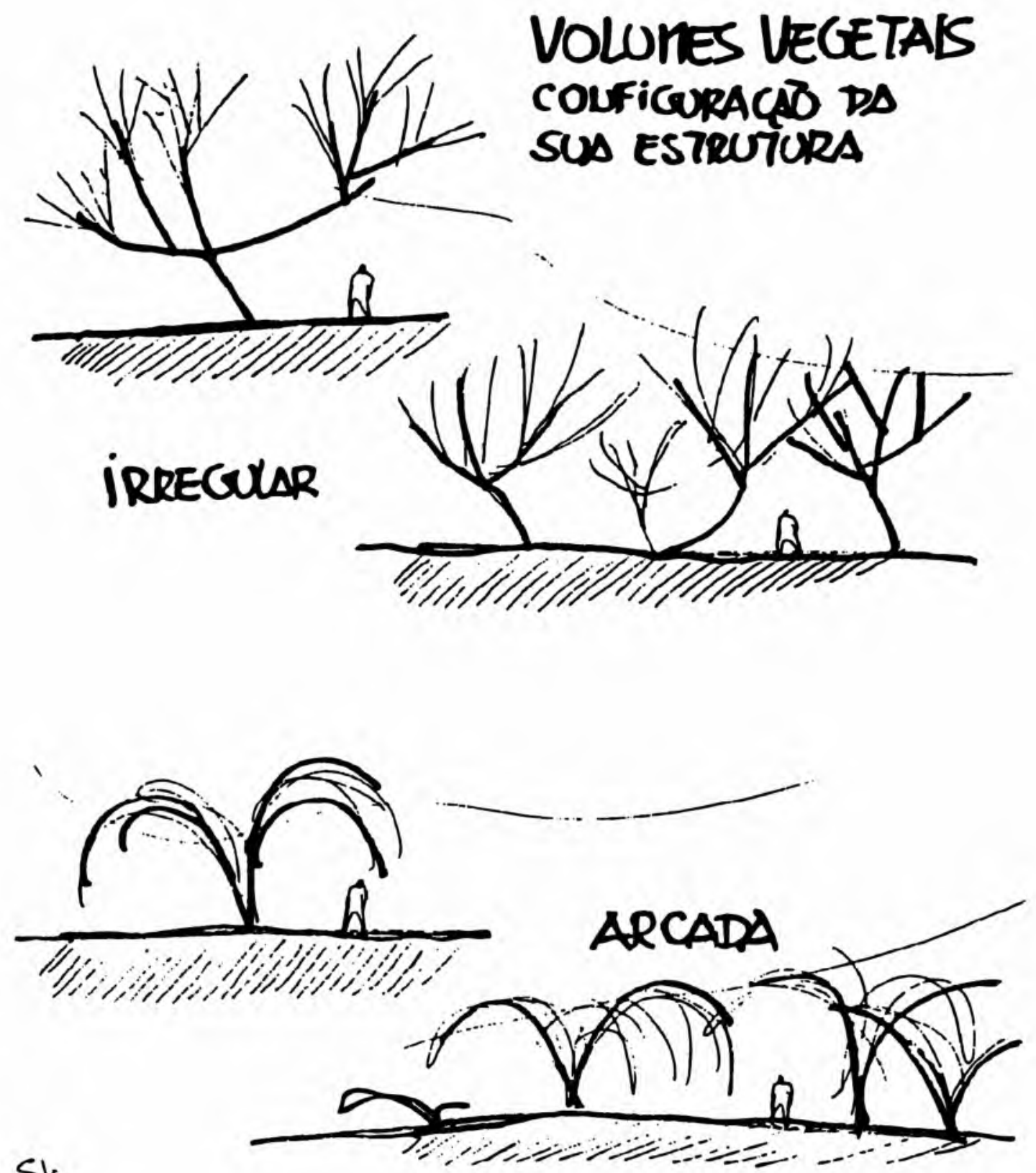

Sos

Transparência - A quantidade de luz que permite em cada espaço determina uma outra característica do espaço - o seu grau de luminosidade.

Um espaço coberto pela copa de um mesmo número deárvores que um outro com igual quantidade, será diferenciado pelo grau de transparência, de penetração daluz possível, da sua claridade. As diferentes espécies vegetais possuem densidade e quantidade de folhagem diferentes: muito densas, densas, médias e ralas, bem como podem variar estas quantidades de acordo com a estaçãodo ano. Isto possibilita uma grande variedade 
de tratamentos espaciais, com elementos vegetais demesmoporte, formae volume, mas de folhagem com características diversas.

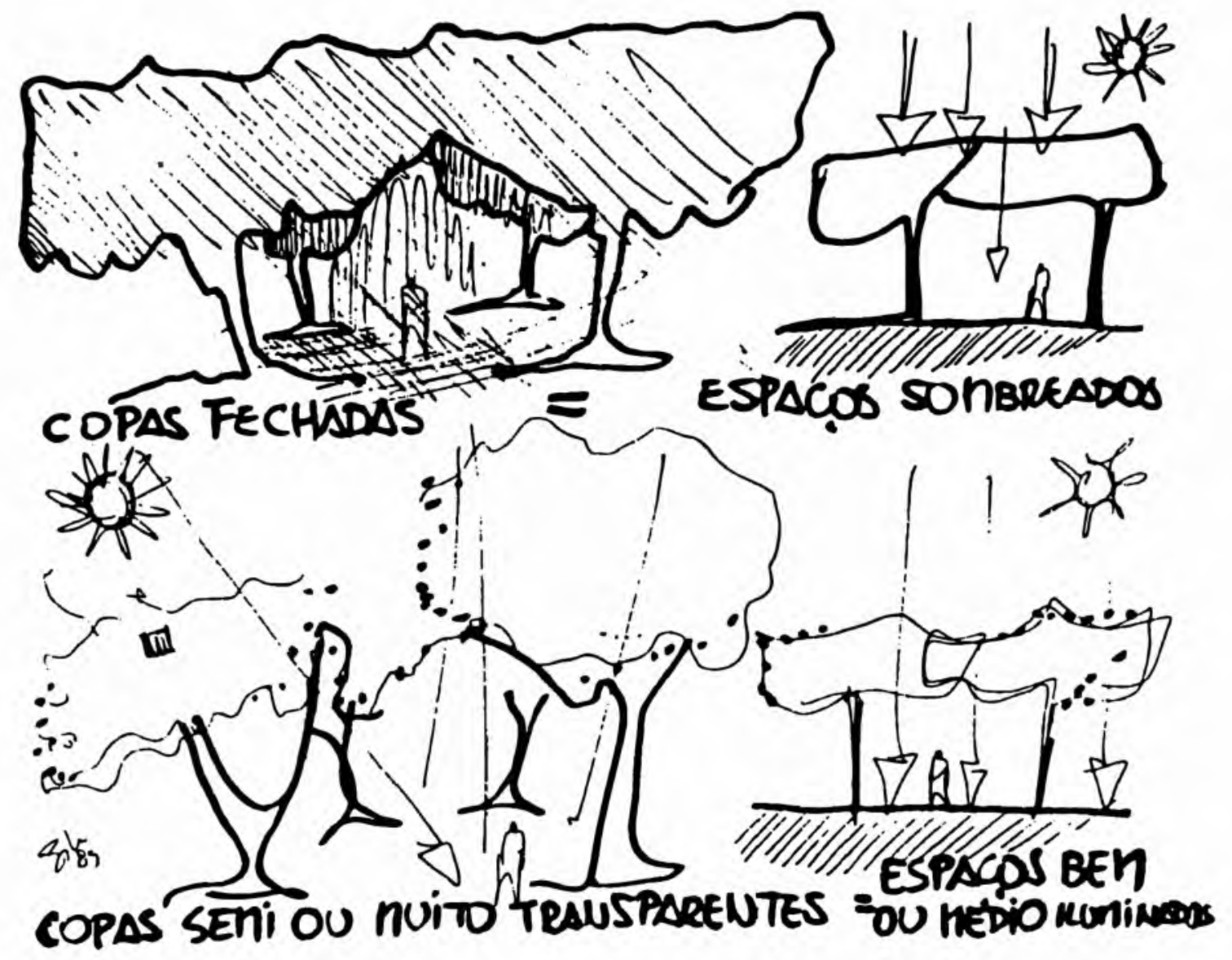

A transparência também é funçãodos tipos de folhagem encontrados, folhas mais finas, mais claras, mais translúcidas, outras opacas, escuras, etc., determinam sua maior ou menor intensidade.

Cor - Um dos elementos básicos a serem considerados na formação de uma paisagem, principalmente no que se refere a vegetação.

Diversos são os tons de verde, vermelho, amarelo e derivados que apresentam os elementos vegetais. Pode-se obter as mais variadas situações de acordocom adisposição das massas de vegetação, tais como recantos sombrios, com pouco brilho, com o predomínio da cor verde escura, espaços claros com o predomínio de amarelos, verdes claros, panos de cor derivados de massas de arbustos e forrações, etc. 
A,utilização de espécie que produzem floração aumenta o rol de possibilidades de escolha com a in trodução de uma variada e maior gama de cores possiveis, tons fortes, claros, brilhantes, os vermelhos amarelos e variáveis, o branco, cores pastéis como o azul, etc.

Tanto cor como transparência são condições sujeitas às variações de clima, luz de acordo com a época do ano e a idade do elemento vegetal - um ser vivo, que adota uma conformação específica de acordo com o tempo, de modo a se adaptar convenientemente ao meio que está inserido.

Textura-De massas vegetais, derivadas daconformação desuafolhagem, troncoseflores, dos claros-escuros produzidos pelo jogo de luz sobre as suas superfícies. Tanto como o fator cor, é um elemento básico a ser considerado na formação e caracterização de cada espaço.

Movimento - Os vegetais, como seres vivos movimentam-se constantemente de uma maneira muitas vezes sutil ao ser humano, em busca da luz, alimento, etc. Devido a sua conformação apresentam diversos graus de flexibilidade das suas diversas partes, variando conforme a espécie, o que permite um movimento variado, conforme a intensidade dos ventos dominantes. Isso confere a cada espaço onde existam elementos vegetais uma certa dinâmica, um certo ritmo, produto da movimentação dos galhos, folhagens, da queda das folhas, etc.

Água - Um elemento básico na configuração geral de um espaço livre. Sua presença introduz movimento, reflexão, tonalidades de azul, verde e cinza, umidade, bem como é fator básico para a vida dos diversos seres vivos, árvores e animais. Sua presença pode ser estrutural, isto é, quando define a organização do espaço, tal como um sistema de lagos em um parque, um rio, um canal, etc., ou complementar quando participa de uma paisagem, mas não define nenhum sistema dę espaços, tais como os bebedouros, fontes, etc.

Conforme a escala e dimensão das superfícies ocupadas por água em ūm espaço livre, conforme a escala do espaço, podem as águas serem usadas como:

Elementos para lazer - lagos, canais, rios, praias, ocupados por banhistas, utilizados para pesca, por pequenas embarcações, etc.

Elementos decorativos - fontes, quedas de água, repuxos, tanques, pequenos canais e lagoas destinados a uma composição visual de um espaço desejado.

Elementos de controle - banhados, alagadiços, etc., que independente de uma função de uso para lazer, são reservados como áreas de enchente em épocas de chuva, de modo a controlar ou minimizar possíveis cheias em aglomerados urbanos. 


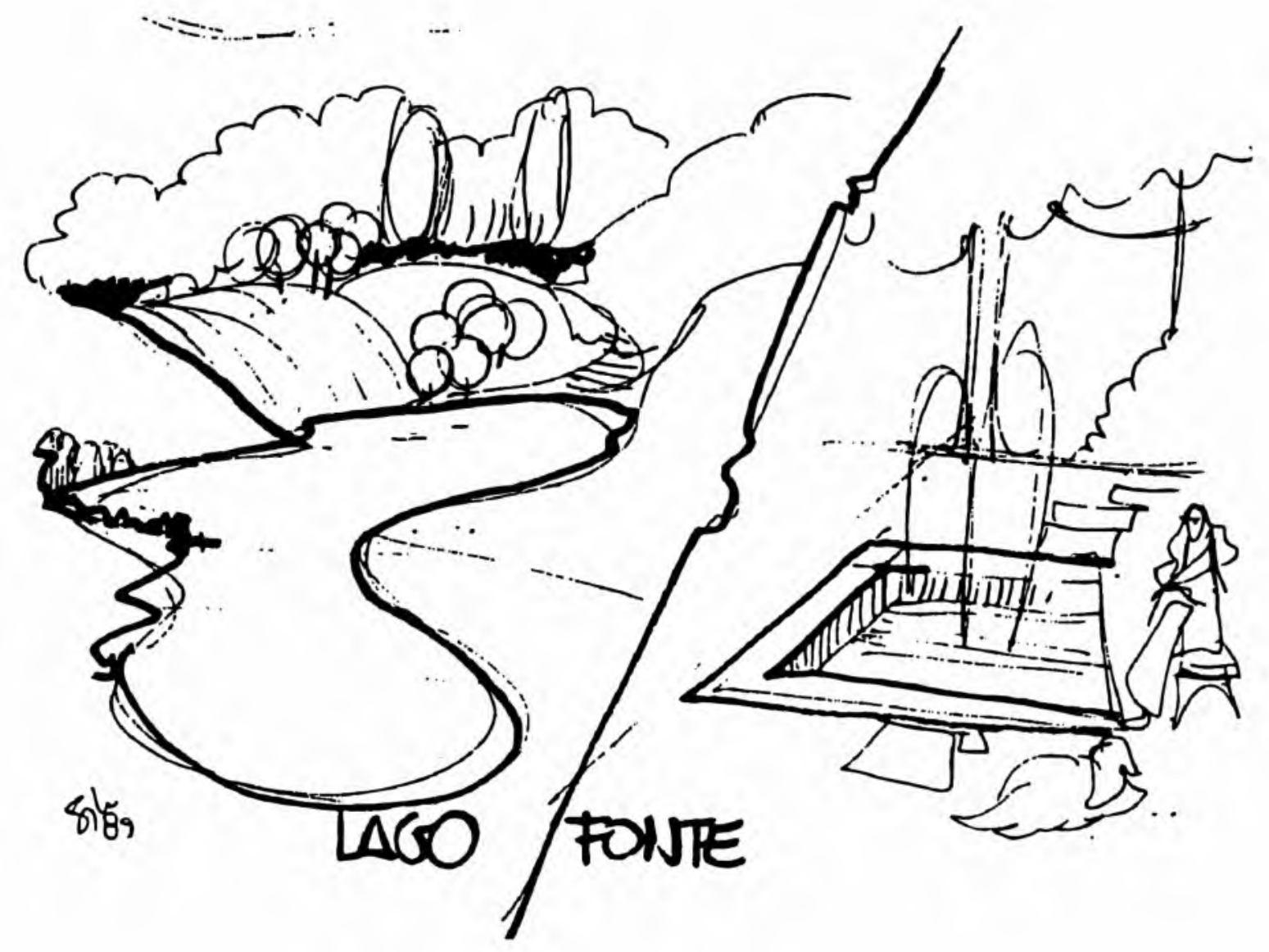

Elementos de preservação - da fauna e flora aquáticas de uma região, os santuários, reservas ecológicas, etc., de uso restrito ao ser humano.

A partir da seleção de suas formas de utilização são localizadas as águas, seus perímetros, profundidades mínimas e máximas, meios de captação e purificação, demarcadas as represas, diques, canais, etc., especificados seus acessos e barreiras.

Volumes Edificados - Os prédios existentes ou a construir são considerados em sua forma e volume básicos, acessos e utilização, sua implantação no meio é definida e também os principais movimentos de terra necessários a sua implantação.

Nesta etapa são definidos os planos de pisos do seu entorno imediato, terraços, escadarias, patamares, gramados, etc., bem como a sua relação com a volumetria plantada, utilizada de modo a valorizar ou diluir edifício. 
Outros Volumes Construídos - Quiosques, molhes, mirantes, marquises, pergolados, viveiros, embarcadouros, muros, pórticos, pontes, etc., volumes complementares aos diversos espaços ou caracterizado, marcos de um ambiente. São indicados seus usos, locação e dimensão, formas básicas e o seu papel no sistema-paisagem a ser criado ou produzido.

PLANO DE ZOIJEAMENTO
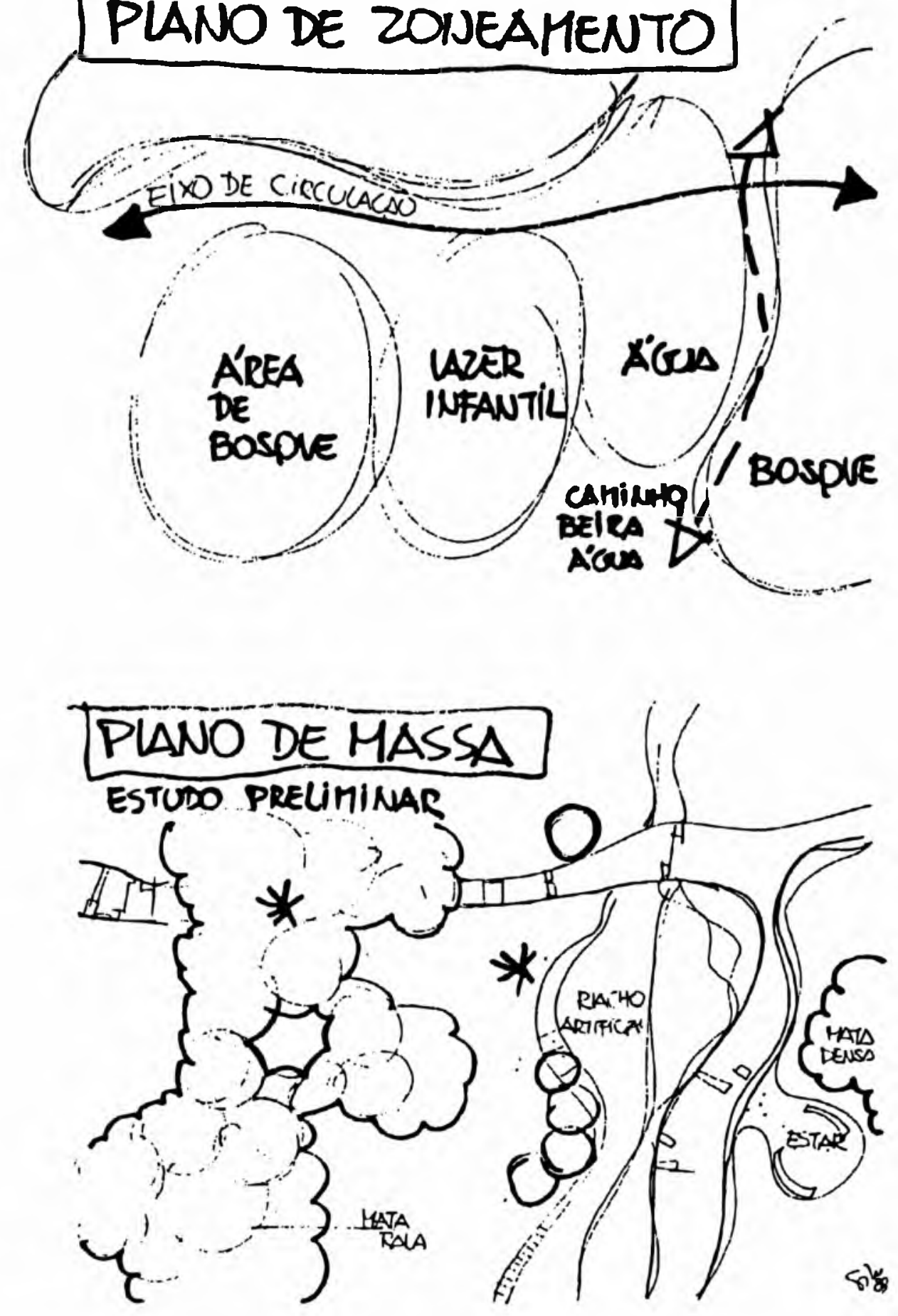

25 
Equipamentos - Volumes ou pisos construídos, de pequeno porte, destinados a atividades específicas de lazer, de esportes, etc. São também volumes complementares dos espaços, das atividades diversas, como os bancos, os bebedouros, luminárias, etc. ou seus determinantes, como os destinados ao esporte, ao lazer infantil. São estes as quadras e campos de esporte, os brinquedos infantis, etc., que para um uso total e adequado aos seus fins devem ter considerados como parâmetros de implantação sua posição no sítio, locados em planos adequados, com proteção aos ventos, insolação controlada, etc.

A localização, dimensionamento básico e caracterização destes últimos é prioritária nesta etapa, bem como a especificação de critérios de localização e uso dos volumes complementares.

Observações:

1 Estas informações sobre um plano de massas são concentradas em uma coleção de desenhos, plantas, croquis e cortes, relatórios e gráficos, de modo a mostrar a imagem desenhada...

2 Também são estabelecidos, para cada espaço, critérios de iluminação e uso de esquemas de drenagemcomo é dada uma visão conjunta da paisagem a ser produzida.

\section{BIBLIOGRAFIA}

CARPENTER, Phillip L., et. al. Plants in the landscape. San Francisco: W. H. Freeman and Co., 1975.

HACKETT, Brian. Planting design. New York: MacGraw Hill Book Company, 1979.

TANDY, Cliff. Paisaje urbano. Madrid: H. Blume Ediciones, 1976. 


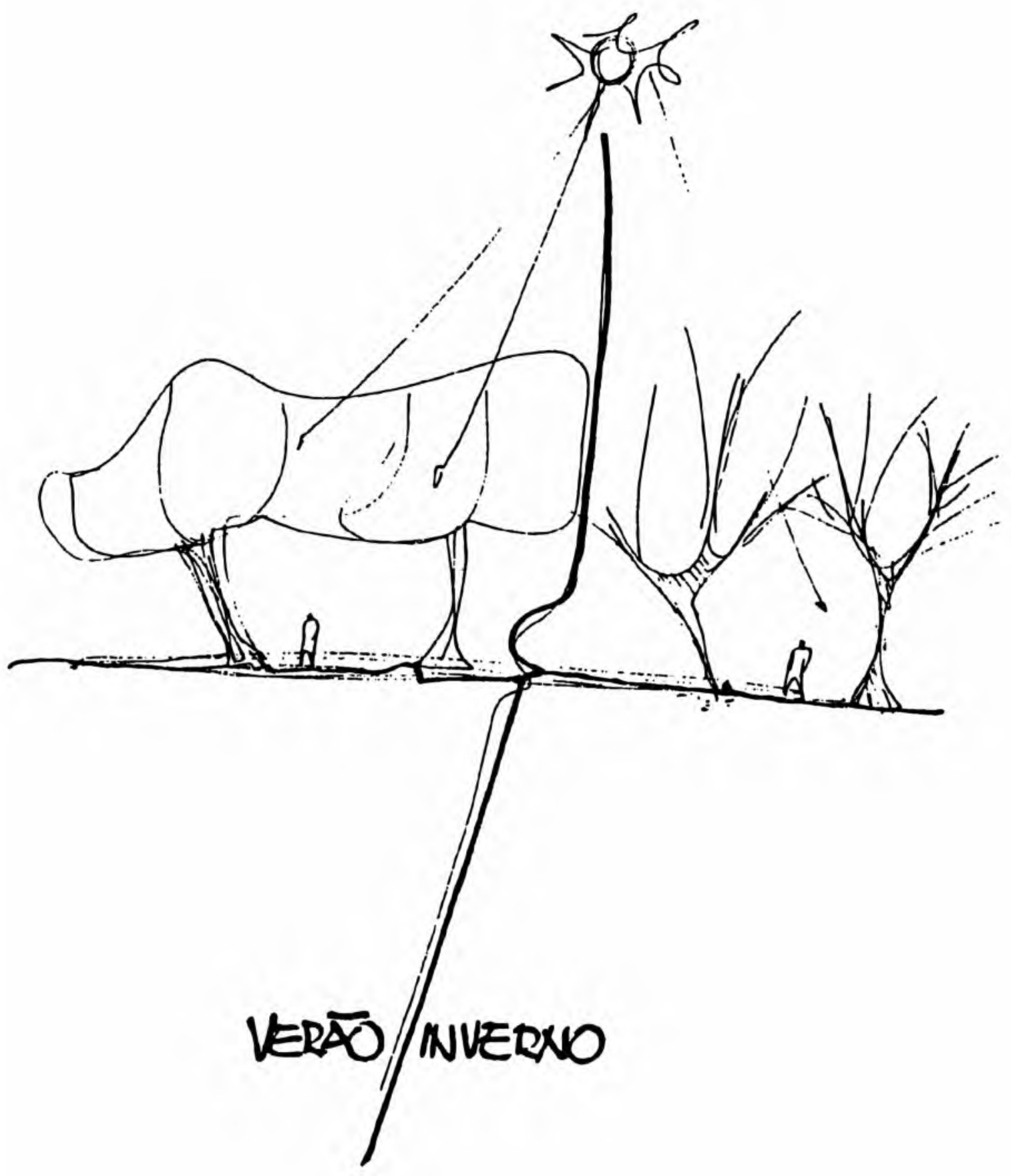

